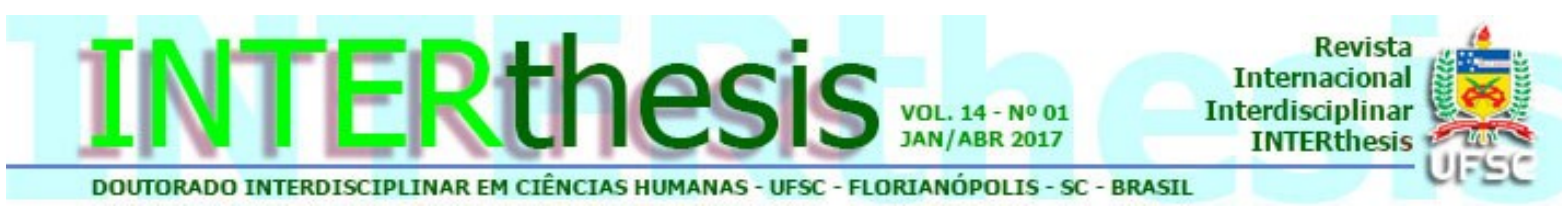

\title{
INTERDISCIPLINARIDADE: DA TOTALIDADE À PRÁTICA PEDAGÓGICA
}

\author{
Fernando José Martins ${ }^{1}$ \\ Maristela Soldá ${ }^{2}$ \\ Noemi Ferreira Felisberto Pereira ${ }^{3}$
}

\section{Resumo:}

Este artigo faz reflexões sobre a interdisciplinaridade no intuito de contribuir na compreensão de tal categoria. Partimos do pressuposto de que a realidade é dinâmica, sendo os sujeitos que escrevem/desenham os circuitos da história, influenciados pelo conjunto de relações sociais em que estão inseridos. Por isso, as discussões teóricas tornam-se necessárias, pois buscam romper com a forma tradicional do conhecimento e de escola. Assim, trabalhar na perspectiva da interdisciplinaridade na proposta de uma escola pode propiciar uma formação para emancipação humana, na qual os sujeitos inseridos têm a tarefa de tornar realidade novas formas de organizar o espaço considerando a totalidade social. Baseada na pesquisa bibliográfica de cunho qualitativa, discorreremos sobre a evolução da ciência buscando apresentar os fatos que possibilitaram as mudanças de paradigmas. Apresentamos, também, discussões sobre a interdisciplinaridade como um caminho para compreensão dos fenômenos na perspectiva da totalidade e finalizamos compreendendo o processo interdisciplinar na prática pedagógica. Verificou-se que a interdisciplinaridade é uma necessidade decorrente da própria evolução da ciência e da realidade social que é, ao mesmo tempo, una e diversa.

Palavras-chave: Interdisciplinaridade. Totalidade. Historicidade. Realidade Social. Prática Pedagógica.

\section{INTRODUÇÃO}

Entendemos que a produção do conhecimento cientifico não é prerrogativa do homem contemporâneo. A evolução da ciência é um processo histórico que desde a Grécia Antiga busca explicações sobre a natureza, o homem e o mundo com pensadores como Sócrates, Platão, Aristóteles.

Na Idade Média a ciência era o estudo de Deus e, assim, a fé precedia o conhecimento. Era a filosofia de Santo Agostinho, Boécio e Tomás de Aquino. Para

\footnotetext{
1 Doutor em Educação pela Universidade Federal do Rio Grande do Sul, Porto Alegre, RS, Brasil. Professor da Universidade Estadual do Oeste do Paraná, Cascavel, PR, Brasil. E-mail: fernandopedagogia2000@yahoo.com.br

${ }^{2}$ Mestranda em Sociedade, Cultura e Fronteiras na Universidade Estadual do Oeste do Paraná, Cascavel, PR, Brasil. Professora da Rede Pública Municipal de Cascavel em Cascavel, PR, Brasil. Email: maristelasolda@hotmail.com

${ }^{3}$ Mestranda em Sociedade, Culturas e Fronteira na Universidade Estadual do Oeste do Paraná, Cascavel, PR. Técnica em Assuntos Educacionais na Universidade Federal da Integração LatinoAmericana, Foz do Iguaçu, PR, Brasil. E-mail: naomiferreira@gmail.com
}

R. Inter. Interdisc. INTERthesis, Florianópolis, v.14, n.1, p.01-18 Jan.-Abr. 2017 
Ranieri (2009) a ordem medieval, a sociedade dos nobres feudais, é naturalizada por Agostinho como um reflexo da ordem dos céus.

Já no Renascimento o homem é o centro, apesar da religião manter seu espaço de saber. Todavia a filosofia, a arte, a política e a moral possuíam os seus respectivos lugares. Nesse sentido, o homem era um ser dinâmico, que faz sua história, produz o seu destino. A atuação filosófica dos Renascentistas não abandou a existência de um Deus, da religião, mas estipulou autonomia do conhecimento humano.

O lluminismo - que tinha em seu contexto o desenvolvimento vertiginoso do capitalismo - marca o desenvolvimento da ciência moderna. Ranieri (2009) discorre que é a época onde a razão é cultivada em busca do progresso do conhecimento e da verdade. É a eterna suspeita sobre a natureza das coisas que requer um método para responder as indagações da razão humana.

Tais passagens não se deram de forma cronológica e estanques, mas foi um processo de idas e vindas que na contemporaneidade mostra a complexidade da sociedade e torna necessária e imperiosa a investigação na sua essência.

Partindo desse pressuposto, qualquer análise no campo das ciências implica tomá-las em relação inseparável entre o conjuntural e o estrutural. Em outras palavras, impõe estudos sobre a categoria interdisciplinaridade e sua relação com a prática pedagógica como uma necessidade que é resultado do próprio desenvolvimento da ciência.

Baseado na pesquisa bibliográfica de cunho qualitativa os autores que fundamentam este estudo na compreensão da categoria da interdisciplinaridade são Alvarenga (2011), Etges (2011), Frigotto (2008 e 2012), Pombo (2008) e Fazenda (2006). E para compreender a educação na perspectiva da totalidade, kosik (1986) Marx (1982), Freitas (2012).

O artigo está organizado em três seções. A primeira destina-se a contextualização da interdisciplinaridade a partir do desenvolvimento da ciência moderna. Em seguida tratamos da relação interdisciplinaridade e totalidade. A terceira seção interliga a interdisciplinaridade e a prática pedagógica no sentido de trabalhar os conteúdos escolares a partir de construções interdisciplinares. 


\title{
2 ANTECEDENTES À INTERDISCIPLINARIDADE
}

Entende-se que a interdisciplinaridade tem suas raízes na história da ciência moderna, a partir do século $X X$. Porém, desde o século $X V$, a ciência passa por diversas mudanças em seus paradigmas e na sua estrutura o que resulta em uma explosão de novos conhecimentos, novas práticas e técnicas de pesquisa.

Pode-se descrever a Ciência Moderna, como aquela que conseguiu articular o método de observação e experimentação com o uso de instrumentos técnicos (sobretudo o telescópio e o microscópio), que começou a se desenvolver, na Europa do século XVI.

O nascimento dessa ciência nova é tido por muitos historiadores como uma revolução, porque na sociedade antiga e na sociedade medieval as investigações sobre fenômenos naturais (terrestres e celestes), organismos vivos, dentre outras, não se valiam do uso da técnica e não concebiam o universo como algo composto de uma mesma matéria uniforme, suscetível à corrosão e à finitude.

Assim, compreender como a ciência descreve esses processos de ruptura epistemológica na história é importante para analisarmos as concepções de interdisciplinaridade presentes, hoje, nas relações teóricas e práticas, bem como suas múltiplas relações e a forma com que a pesquisa científica se expressa.

Nesse sentido, pretendemos superar a análise da história pela ótica cíclica, vale a tentativa de compreendê-la pela ótica elipsoidal, pois não se inventa a roda, mas se busca uma maneira de fazê-la funcionar e servir a diferentes mecanismos, antes não atendidos, como expressa Alvarenga (2011)

\begin{abstract}
A questão que se apresenta é a de quais ordens de transformações representariam ou caracterizam a mencionada ruptura ou corte epistemológico que marcariam o início da ciência moderna, e como entendê-la? Segundo Lima Vaz (2002, p. 29), esse processo teve seu momento decisivo no século XIII, quando se registra a "entrada definitiva da razão aristotélica no universo teológico cristão", universo esse característico desde o início da Idade Média. (ALVARENGA, 2011, p. 9).
\end{abstract}

Essas transformações históricas e as condições sociais e estruturais pelas quais a Europa passou neste período - crises, pestes, guerras - foram determinantes para o surgimento da ciência moderna no mundo ocidental como uma possibilidade de reinterpretar e construir o conhecimento científico, sob uma nova perspectiva.

Com a decadência do modo de produção feudal, surgem às novas técnicas de produção, migra-se a mão-de-obra da agricultura para funções como artesanato 
e o comércio, nos pequenos burgos localizados no entorno dos feudos. Isso torna necessário e emergente a abertura de rotas comerciais por toda a Europa e ampliação dos centros urbanos, florescendo a circulação do dinheiro.

Há um momento histórico representativo dessa transição que queremos explorar e evidenciar. A Revolução Industrial, que é um fato marcante de tal transformação. Para Beer (2006), este período representa: a transição do artesanato para a mecanização; do trabalho que era realizado por uma única pessoa para a divisão do trabalho ou trabalho compartimentado; o crescimento das linhas de produção; a origem do proletariado. Nas palavras do autor,

\begin{abstract}
A Revolução Industrial que, pouco a pouco, iria fazer o mundo inteiro trilhar pela senda de uma nova civilização. Suas consequências foram incomparavelmente mais vastas e mais profundas que as de todas as revoluções anteriores, porque ela lançou as bases de uma nova ordem social e criou os meios para a superação da miséria, da opressão e da diferença de classe. (BEER, 2006, p.355)
\end{abstract}

É necessário alertar que a apresentação sintética desses momentos históricos distintos, da focalização em um fato, como a revolução industrial, pode-se manifestar como um reducionismo, contudo, o que se quer aqui, é localizar a matriz da racionalidade científica disciplinar, que em nosso entendimento, se fortalece e assume seu formato no período referido. Assim, no pensamento moderno, conforme apresenta Aranha e Martins (2005), o renascimento científico do século XVII é tratado não como uma simples evolução do pensamento científico, mas uma verdadeira ruptura que implicou outra concepção de saber, por conta da novidade do método instituído. Destacam-se novas técnicas em busca da verdade que se utilizam dos métodos da observação, pesquisa e experiência.

As autoras, ainda, pontuam que o contexto da emergência da burguesia, desenvolvimento da economia capitalista, revolução comercial, renascimento das artes, das letras e da filosofia desenvolveu um novo indivíduo, confiante na razão e no poder de transformar o mundo.

Pode-se se notar que tais premissas se fortalecem contemporaneamente, a concepção renascentista se desenvolveu para a consolidação de correntes filosóficas iluministas com o princípio na razão. Nestas existe a "crença" nas ciências que são responsáveis pela criação de todas as soluções necessárias para os problemas que as sociedades humanas enfrentam.

Essa ideia é consolidada pelo modo de produção capitalista, que expropria a mão-de-obra do trabalhador e tem na mais-valia sua fonte de riqueza. 0 
conhecimento, por sua vez, é marcado pelas formas simplificadas, dicotômicas. Eis o pensamento cartesiano, o positivismo, o estruturalismo. Estes têm como base a disciplinaridade e a experimentação.

Este modelo de racionalidade, herdado a partir do século XVI e consolidado no século XIX, vislumbra uma única forma de atingir o conhecimento verdadeiro. Para Boaventura Santos (2010) este paradigma é dominante e totalitário e apresenta distinções fundamentais aos modelos de saberes aristotélicos e medievais. Assim,

A fronteira que se estabelece entre o estudo do ser humano e o estudo da natureza não deixa de ser prisioneira do reconhecimento da prioridade cognitiva das ciências naturais, pois, se, por um lado, se recusam os condicionantes biológicos do comportamento humano, pelo outro, usam-se argumentos biológicos para fixar a especificidade do ser humano. (SANTOS, 2010, p. 40)

Os desdobramentos da lógica moderna para categorização que conhecemos, delineia as ciências naturais pautada na materialização da ideia de mundo estável e determinável por meio das leis da física e da matemática. Já as ciências sociais como uma absorção das ciências naturais, de forma mecanicista que aplica os princípios epistemológicos e metodológicos do estado da natureza.

Completando a lógica moderna, quanto à especialização do saber, Pombo (2008) versa que a particularização do conhecimento científico não é específica da atualidade ocidental. Para a autora, a especialização "é uma condição de possibilidade do próprio progresso do conhecimento, expressão das exigências analíticas que caracterizam o programa do desenvolvimento da ciência que nos vem dos Gregos e que foi reforçado no século XVII com Descartes e Galileu" (POMBO, 2008, p. 16).

Nesse sentido, a autora apresenta que apesar das diferenças que os distinguem cada momento histórico, eles compartilham de uma mesma característica metódica que é dividir o objeto de estudo para estudar finamente os elementos constituintes e, depois, recompor o todo a partir daí.

Desta forma, constatamos que a própria evolução da ciência colocou em crise o modelo hegemônico da decomposição, da experimentação, da quantificação e da rigorosidade da matemática. $\mathrm{O}$ avanço do conhecimento nas áreas da microfísica, da química e da biologia tem mostrado que se faz necessário considerar a relação do objeto com o todo.

Aranha e Martins (2005) fazem a comparação entre a física moderna - que trouxe a novidade da experimentação e da matematização - e a física antiga que era 
qualitativa e baseada nas qualidades intrínsecas das coisas. As autoras trazem o exemplo de Galileu que observava e realizava experiência em laboratório, usando instrumentos e descrevia quantitativamente os fenômenos. Elas salientam que "no século XX a ciência deu passos gigantescos, e as descobertas se deveram a diversos fatores, entre os quais não se pode descartar a fecunda interação entre a ciência e a tecnologia". (ARANHA e MARTINS, 2005 p.189-191)

Uma das características que, do ponto de vista dominante, aprimora elementos da revolução industrial e dos processos produtivos, que tem impactos diretos na ciência e tecnologia, é a transição das matrizes mecânicas para microeletrônicas, devido ao avanço tecnológico. Está é uma marca que desprende do natural e traz uma mudança no pensar, no manusear e na elaboração da própria ciência, esse conceito da construção do paradigma científico após a modernidade pode ser entendido na descrição de Alvarenga (2011) como

\footnotetext{
A discussão do tema interdisciplinaridade inscreve-se em um amplo movimento de reflexão crítica sobre o tipo de avanço da ciência e da tecnologia no mundo moderno, associado ao que conhecemos como tecnociência [...] do fato dessa tecnociência comandar o futuro das sociedades sem comandar a si próprio. (ALVARENGA, 2011, p. 3)
}

O conjunto das características sociais citados anteriormente, o processo de reconstrução dos paradigmas técnico-científicos, trazem impactos para a organização acadêmica da ciência. Muitos autores versam sobre tal lógica de organização e como as disciplina se reconfiguram a partir do debate interdisciplinar. Devido ao acúmulo de produção sobre a temática, elegemos Olga Pombo (2008) para uma exposição acerca das formações disciplinares.

A autora concentra essas formações interdisciplinares em três grupos, que mostram o esforço da ciência para superar o caráter disciplinar que marcou boa parte da modernidade. Segundo a autora, já é possível identificar a existência de interciências, "não são duas disciplinas, são várias, e é impossível estabelecer qualquer espécie de hierarquia entre elas" (POMBO, 2008, p.25). Assim como as ciências de fronteira em que "novas disciplinas híbridas que se constituem pelo cruzamento de duas disciplinas tradicionais" (POMBO, 2008, p.25). O terceiro grupo apontado por Pombo (2008), que busca ultrapassar o nível disciplinar, é o cruzamento de ciências puras e aplicadas (interdisciplinas), que se ligam, de forma descentrada, assimétrica, irregular, capaz de resolver um problema preciso.

A autora cita como exemplos as ciências cognitivas e as ciências da R. Inter. Interdisc. INTERthesis, Florianópolis, v.14, n.1, p.01-18 Jan.-Abr. 2017 
computação. São conjuntos de disciplinas que se encontram de forma irregular e descentrada para colaborar na discussão de um problema comum. A juventude urbana, o envelhecimento, a violência, o clima ou a manipulação genética, por exemplo, são novidades epistemológicas que só um enfoque interdisciplinar pode procurar dar resposta.

Nesse sentido, Aranha e Martins (2005) assinalam que no final do século XX surgiram as chamadas ciências híbridas, nas quais interagem cientistas da física, da química, da biologia, da astronomia, aliados a técnicos das áreas da informática, engenharia e medicina. Esses pesquisadores geralmente são geneticistas moleculares, bioquímicos, biofísicos e peritos de inúmeras especialidades novas, que fazem suas pesquisas compartilhando informações.

Dessa forma, pontuam as autoras que tem ocorrido uma certa diluição das fronteiras das ciências, o que Ihes confere um caráter interdisciplinar. Assim, o "conhecimento se processa por meio da superação de crise de paradigmas que exigem uma postura mais despojadas por parte de cientistas e filósofos, a fim de que, com maior disposição do espirito, possam rever suas próprias certezas" (ARANHA e MARTINS, 2005, p. 192).

Entendemos, a partir do exposto, como o pensamento científico se reproduz a partir das relações materiais de determinada sociedade e que a interdisciplinaridade nasce em decorrência da evolução da ciência. O conhecimento cientifico partiu do universal para o particular e, dada a complexidade atual e seu desenvolvimento, a interdisciplinaridade é uma necessidade da sociedade contemporânea.

\section{INTERDISCIPLINARIDADE COMO UM CAMINHO PARA COMPREENSÃO DOS FENÔMENOS NA PERSPECTIVA DA TOTALIDADE}

A partir da crise da ciência no modelo clássico - exata, objetiva, quantificável, verdadeira, neutra, pragmática, ou seja, na perspectiva positivista - emerge a discussão sobre a interdisciplinaridade. Para Etges (2011)

Desde que os homens passaram a pensar em termos formais, romperam com a unidade entre o sujeito e o objeto, homem e natureza dada. Tem sido enorme a dificuldade de explicar o hiato criado e até hoje a maioria das soluções propostas para explicar a ciência estão impregnadas de caráter metafisico. $O$ fracasso destas tentativas de explicação levou os cientistas a empregar uma descrição puramente pragmática e utilitária para suas atividades, resvalando para a razão puramente instrumental. (ETGES, 2011, p. 60) 
Assim, a interdisciplinaridade é apontada como uma possibilidade de superação do conhecimento fragmentado. Então, como compreender a interdisciplinaridade? Tentaremos pelo viés que todo conhecimento deve necessariamente estar em diálogo e ser passível de confirmação, de negação, de questionamento, de complementação, de ampliação... de e por diferentes aspectos.

Salientamos que não é o confronto entre as disciplinas, mas sim, a busca incessante das interfaces entre as mesmas, conforme aponta Alvarenga (2011)

A proposta de integrar o conhecimento e humanizar a ciência, tendo como princípio básico considerar o homem como ponto de partida e ponto de chegada do conhecimento cientifico. [...] A interdisciplinaridade busca responder, assim, a problemas gerados pelo próprio avanço da ciência moderna disciplinar, quando esta se caracteriza como fragmentadora e simplificadora do real; fato que resulta na multiplicação espetacular de novas áreas do conhecimento. (ALVARENGA, 2011, p. 20-21)

As áreas disciplinares nos darão bases científicas para compreender 0 processo como um todo. É importante ressaltarmos que para se fazer a interdisciplinaridade é necessário que o pesquisador/educador domine a área do conhecimento e a disciplina a qual pretende ministrar suas aulas.

Assim, entendemos que a interdisciplinaridade é mais que uma corrente epistemológica. Podemos dizer que é como se constrói a relação entre os saberes. Concordamos com Alvarenga (2011) que discorre:

\begin{abstract}
A interdisciplinaridade se apresenta na atualidade... como a nova forma de conhecimento, alternativa ao disciplinar, mas igualmente complementar. Alternativa e complementar, e igualmente inovadora, por completar, em termos de princípio geral, a proposta de um saber que busca relacionar saberes, que propõe o encontro entre o teórico e o prático, entre o filosófico e o científico, entre as ciências e a humanidades, entre a ciência e a tecnologia, a interdisciplinaridade apresenta-se, assim, como um saber que é da ordem do saber complexo. (ALVARENGA, 2011 p. 26 e 27)
\end{abstract}

Apreendemos que a socialização do conhecimento é uma necessidade do homem como ser social com suas múltiplas relações. Neste contexto, o conhecimento é mais complexo, supera a arbitrariedade abstrata das disciplinas.

Nesse sentido, Frigotto (2008) aponta que o trabalho o interdisciplinar na produção e na socialização do conhecimento no campo das ciências sociais e no campo educativo que se desenvolve no seu bojo, não decorre de uma arbitrariedade racional e abstrata, mas origina-se de uma necessidade, pois a forma do homem produzir-se enquanto ser social e enquanto sujeito e objeto do conhecimento social é que torna imperiosa tal abordagem.

O autor destaca que "a produção do conhecimento e sua socialização ou R. Inter. Interdisc. INTERthesis, Florianópolis, v.14, n.1, p.01-18 Jan.-Abr. 2017 
negação para determinados grupos ou classes não é alheia ao conjunto de práticas e relações que produzem os homens num determinado tempo e espaço." (FRIGOTTO, 2008, p. 43). É justamente no sistema social com a luta antagônica de sujeitos com interesses divergentes que a ciência encontra sua efetiva materialidade histórica.

Frigotto (2008) aponta que o homem utiliza-se da natureza e a transforma-se para satisfazer suas necessidades, bem como produz o conhecimento que the é inerente a sua prática social. Segundo ele, essa intervenção tem caráter dinâmico, pois novas necessidades criadas pelo homem necessitam de novos conhecimentos e, desta forma, produz significados, possibilitando a reflexão e a constituição de novos referenciais. Nessa perspectiva,

\begin{abstract}
Uma primeira consequência é que o trabalho interdisciplinar não se efetiva se não formos capazes de transcender o plano fenomênico, heranças fortes do empirismo e do positivismo. Todavia essa é uma segunda consequência, ele também não se efetiva se cairmos no reducionismo estruturalista que abandona o plano histórico-empírico e se locupleta no plano discursivo [...] aqui as categorias assumem a autonomia face ao real histórico e apresentam como um a priori, camisas de forças que amordaçam o tecido complexo da realidade. (FRIGOTTO 2008 p. 44)
\end{abstract}

Ao considerar o homem como sujeito histórico, em sua totalidade, de forma dinâmica e processual, entendemos que essa totalidade é definida pelas condições materiais existentes em um espaço e tempo definido, onde a noção de totalidade, na perspectiva do materialismo histórico, não se refere ao conhecimento total e completo do objeto, mas à recusa à fragmentação.

É neste sentido, Farias (2015) ressalta que "o caráter específico da contradição não é absoluto e não tem sentido quando separado da totalidade. $O$ especifico não tem valor se não em relação à totalidade, na medida em que ambos são inseparáveis." (FARIA, 2015, p. 93)

A realidade concreta é um conceito central para o materialismo dialético. Para Karl Marx (1982), a realidade não é caótica, desordenada ou fragmentada, incompreensível em sua totalidade. Ela possui uma dimensão concreta, que deve ser apreendida, trazendo a representação caótica da realidade (abstração) inicialmente para o plano do concreto idealizado (pensado) e, a partir de instrumentos de análise, chegar à totalidade concreta, síntese de muitas determinações e unidade do diverso.

Outrossim, a realidade concreta também não é fruto do pensamento humano, ou sua consciência, mas justamente o contrário. Para Frigotto (2008), o R. Inter. Interdisc. INTERthesis, Florianópolis, v.14, n.1, p.01-18 Jan.-Abr. 2017 
entendimento da realidade concreta, em contraposição a totalidade caótica, vazia, é imprescindível para compreendermos a interdisciplinaridade como necessidade imperativa na construção do conhecimento social.

No princípio da totalidade é onde se estabelece relações para se entender o objeto e suas contradições. Uma das categorias fundamentais do processo de produção dialética do conhecimento. Porém, não pretende conhecer todos os aspectos da realidade, pois

Se a realidade é entendida como concreticidade, como um todo que possui sua própria estrutura (e que portanto, não é caótico), que se desenvolve (e, portanto, não é imutável nem dado uma vez por todas), que se vai criando (e que, portanto, não é um todo perfeito e acabado no seu conjunto e não é mutável apenas em suas partes isoladas, na maneira de ordená-las), de semelhante concepção da realidade concepção da realidade decorrem certas conclusões metodológicas que se convertem em orientação heurística e princípio epistemológico para estudo, descrição, compreensão, ilustração e avaliação de certas seções tematizadas da realidade. (KOSIK, 1986, p.36)

O concreto é, desse modo, interpretado como uma totalidade internamente dividida das várias formas de existência do objeto, uma combinação única do que é característico apenas do objeto dado. Assim, a unidade concebida é percebida não através da similaridade dos fenômenos um com o outro, mas, ao contrário, através de suas diferenças e oposições.

A busca pela superação da fragmentação, de olhar para a realidade como uma totalidade, formada por diferentes dimensões que se interpenetram, é um objetivo nunca plenamente atingido. Dessa forma, para além de uma proposta teórica, a interdisciplinaridade se consolida como práxis, a partir do trabalho coletivo e da análise dos avanços e limites destas experiências concretas.

É nesse contexto que a necessidade da interdisciplinaridade torna-se fundamental para e na produção do conhecimento. Essa premência se funda no caráter dialético da realidade social que na vertente aqui defendida "é, ao mesmo tempo, una e diversa[...], o caráter uno e diversos da realidade social nos impõe distinguir os limites reais dos sujeitos que investigam dos limites do objeto investigado". (FRIGOTTO, 2008 p. 43-44).

Portanto, a interdisciplinaridade é uma necessidade e uma forma de superar a visão fragmentada nos processos de produção e socialização de conhecimentos na perspectiva da totalidade. Por isso, ela é fundamental para transmissão do saber sistematizado e para a prática pedagógica dos educadores. 


\section{INTERDISCIPLINARIDADE E A PRÁTICA PEDAGÓGICA}

O que caracteriza a interdisciplinaridade é a sua ação no e pelo trabalho, na busca constante de produção de novos conhecimentos. Assim, a relação que propomos da categoria interdisciplinaridade e a prática pedagógica está firmada "na própria gênese e no fundamento da própria produção do saber, e não se funda na busca de alguns elementos comuns que deveriam ser descobertos para chegar a uma espécie de denominador comum, ou a uma unidade global." (ETGES, 2011, p.74)

Partilhamos das palavras de Etges (2011) concordando que tais buscas não levariam a nada, pois estariam fundadas em um nível metafisico, quando na realidade devem se alicerçadas no trabalho dos cientistas e educadores. Para o autor, esta visão simplista parte da lógica imanente do trabalho e vê a ciência como produção de novos mundos, adequados ao sujeito e a inteligência de onde ela provém, a ciência constituiu uma totalidade fechada, completa em si, e só tem existência pela sua exteriorização na linguagem.

Assim, o educador ao planejar sua aula leva em consideração a necessidade de superar a dicotomia existente entre o que chamamos de ensino e o que chamamos de pesquisa, (uma dicotomia que pode se basear na ruptura entre "planejamento e execução" base da "administração científica" taylorista) manifesta no distanciamento entre ação docente e trabalho de planejamento, seleção e construção dos conteúdos escolares, principalmente a consecução de tais ações vinculadas a realidade na qual a prática educativa é realizada.

Reconhecendo tal situação a ação docente parte da realidade dos educando, o vínculo da escola com a vida, aquilo que eles conhecem. Busca-se das diversas áreas do conhecimento científico formas para compreender o processo como um todo. Fiod (2012) destaca que o educador deve desenvolver metodologias em sala de aula que leve o estudante compreender o mundo em suas múltiplas relações.

A pedagogia interdisciplinar se propõe a unificar o saber mediante a interação das disciplinas cientificas, dos seus conceitos e procedimentos. Segundo essa perspectiva, o saber unitário pressupõe a superação da dicotomia teórica e prática presente nas cisões entre pesquisa e ensino, educando e sociedade, pesquisa e ação (FIOD, 2012, p. 168)

A contribuição das diversas ciências na produção do saber escolar com o propósito de um processo de emancipação humana, onde todos tenham condições de pesquisar, de opinar e decidir juntos, uma postura de desenvolvimento do ser 
humano de forma integral deve considerar que

\begin{abstract}
A interdisciplinaridade na escola não pode consistir na criação de uma mistura de conteúdos e métodos de diferentes disciplinas. Estes procedimentos não só destrói o saber posto, mas acaba também com qualquer aprendizagem. Só depois de aprendido e dominado o construto, o educando deve ser encorajado a transcodificá-lo para sua vida cotidiana, para seus irmãos menores, para o grupo de trabalho na escola, para o computador. [...] O mundo do vivido, do analógico, do imediato são contextos que a atividade interdisciplinar precisa atingir, para dissolvê-los e transformá-los em estrutura de pensamento, de ciência, de conhecimento. (ETGES, 2011, p.92-88)
\end{abstract}

Ao transformar o mundo vivido, a realidade do educando em conhecimento, utilizamos de modos, formas, metodologias, procedimentos de reconectar a ciência com a vida e os elementos da vida, rompemos com a forma fragmentada de fazer ciência. Com o processo interdisciplinar o educando tem condições de compreender os conteúdos em diversas dimensões: política, social, produtiva, econômica, técnica.

Em outras palavras, a abordagem interdisciplinar propicia a formação omnilateral do educando, entendida como aquela que tem por finalidade o desenvolvimento do sujeito em todas as suas dimensões, considerando a especificidade do ser e as condições objetivas e subjetivas na qual está inserido. (FRIGOTTO, 2012). Nesse sentido,

A questão da interdisciplinaridade é, portanto, uma temática fundamental
para a conceituação da ciência pedagógica e para a mudança da forma
como se dá a produção do conhecimento no interior das faculdades de
educação. A teoria pedagógica também depende dessa mudança. [...] A
interdisciplinaridade diz respeito ao uso das categorias e leis do
materialismo dialético, no campo da ciência. Na realidade, a ausência
destas categorias e leis faz com que a interdisciplinaridade seja usada como
forma de aumentar artificialmente a relação entre áreas de conhecimento.
Tais áreas têm alto nível de intercomunicação na realidade objetiva, no
mundo, mas foram desenvolvidas fragmentariamente, dentro de uma
metodologia e de uma classificação de ciência positivistas. (FREITAS, 2012,
p. 91)

Desta forma, entende-se que a interdisciplinaridade é um suporte pedagógico fundamental que tem na realidade social o eixo que orienta tudo que vai ser ensinado e apreendido, qual seja: a vida. Isso subsidia a definição de conteúdo e aprofundamento dos conhecimentos podendo facilitar o processo de ensino e aprendizagem. Possibilitando a aquisição de novos conhecimentos, a partir da realidade vivida, da troca, do diálogo, da pergunta.

Fazenda (2006) apresenta que uma propositura interdisciplinar necessita de uma nova práxis e da coletividade, segundo ela,

Um projeto desta natureza pressupõe a formação de professor/pesquisador, daquele que busque a redefinição contínua de sua práxis, e de uma

R. Inter. Interdisc. INTERthesis, Florianópolis, v.14, n.1, p.01-18 Jan.-Abr. 2017 
instituição que invista na superação dos obstáculos de ordem material, cultural e epistemológica, enfim, num projeto coletivo. $\mathrm{O}$ enfrentamento aos obstáculos de ordem cultural e epistemológica não ocorre no isolamento, mas na medida em que a instituição caminhar para uma troca efetiva, seja com a universidade, seja com as demais escolas de $1^{\circ}$ e $2^{\circ}$ graus. (FAZENDA, 2006, p. 51)

Assim, a interdisciplinaridade é uma forma de trabalhar e reorganizar os conteúdos escolares a fim de conectar as dimensões isoladas, obtendo uma visão mais ampla da realidade que, tantas vezes, aparece fragmentada pelos meios de que dispomos para conhecê-la, deve ser compreendida como processo e não como um conjunto de procedimentos a ser seguido.

Frigotto (2008) assinala que este trabalho se dá através de um planejamento docente que vá além das disciplinas, conseguindo construir em conjunto o conhecimento sistematizado, porém, de forma integral. O autor apresenta, ainda, duas condições fundamentais para entendermos a prática interdisciplinar. Em seu entendimento, a interdisciplinaridade não se implementa "se não formos capazes de transcender a fragmentação e o plano fenomênico [...] e se cairmos no reducionismo estruturalista que abandona o plano histórico-empírico e se locupleta no plano discursivo" FRIGOTTO, 2008, p. 44)

Desta forma, as interconexões que acontecem nas disciplinas podem facilitar compreensão dos conteúdos de forma integrada. Esta abordagem pode aprimorar o conhecimento do educando. Para haver interdisciplinaridade deve haver estruturas permanentes que a possibilitem a pesquisa interdisciplinar.

Nesse sentido, a "interdisciplinaridade é entendida como interpenetração do método e conteúdo entre a disciplina que se dispõem a trabalhar conjuntamente a um determinado objeto de estudo" (FREITAS 2012, p. 91). Na interdisciplinaridade existe interação em nível de método e conteúdo. Essa integração "ocorre durante a construção do conhecimento, de forma conjunta, desde o início da colocação do problema. O conhecimento é gerado em um nível qualitativo diferente do existente em cada disciplina auxiliar". (FREITAS 2012, p. 91)

Dessa forma, a interdisciplinaridade pressupõe um trabalho integrado com as áreas do conhecimento da proposta pedagógica, na garantia dos objetivos da aprendizagem e para que os educandos aprendam a olhar o mesmo objeto de conhecimento na perspectiva dos diferentes componentes curriculares.

Em Marx (1982), vamos do concreto caótico ao abstrato para retomar ao concreto, em novo patamar, ou seja, o recurso da abstração é necessário para 
entender o concreto em suas múltiplas determinações. Da mesma forma, o estudo das partes é uma necessidade, já que não captamos o todo de uma vez, precisamos dividir, recortar, para podemos ver o todo melhor.

Assim, é preciso ter ciência disciplinar que aprofunde aspectos particulares da realidade. Porém, o recorte disciplinar é um recurso da mente humana para ver o todo de forma mais articulada e orgânica. Nesse sentido, Frigotto (2008) assinala que

\begin{abstract}
O trabalho interdisciplinar se apresenta como uma necessidade imperativa pela simples razão de que parte que isolamos ou arrancamos "do contexto originário do real" para poder ser explicada efetivamente, isto é, revelar no plano do pensamento e do conhecimento as determinações que assim a constituem, enquanto parte tem que ser explicitada na integridade das características e qualidades da totalidade. É justamente no exercício de responder a esta necessidade que o trabalho interdisciplinar se apresenta como um problema crucial, tanto na produção do conhecimento quanto nos processos educativos de ensino. (FRIGOTTO, 2008 p. 48)
\end{abstract}

Entende-se, assim, que a interdisciplinaridade traz elementos para questionar a fragmentação das diferentes áreas do conhecimento, porém não desvalorizam as disciplinas. Cabe aos educadores, em suas práticas pedagógicas, buscarem metodologias que conectem estas áreas e consigam obter uma relação epistemológica entre as disciplinas e a ligação do ensino com a realidade material que o educando está inserido.

\title{
4 CONSIDERAÇÕES FINAIS
}

A partir das reflexões realizadas, compreendemos que o homem sempre buscou a aprendizagem. Todavia, o conhecimento científico é condicionado pela materialidade que os sujeitos estão inseridos. Dessa forma, ele não é neutro, sempre verdadeiro, exato e quantificável, como preconiza o positivismo.

Observamos que a realidade complexa que vivemos na atualidade é resultado da evolução do conhecimento, principalmente a partir da Ciência Moderna com o desenvolvimento da física quântica, da microfísica, da química, da biologia que mostra a necessidade de considerarmos a relação do objeto de estudo com o todo.

Constatamos, assim, que a necessidade do trabalho e da abordagem interdisciplinar é imperativo por propiciar a busca da totalidade e a crítica à forma fragmentária de produção da vida humana em todas as suas dimensões e, especificamente, na produção e socialização do conhecimento e na construção de 
novas relações sociais que rompam com a exclusão, a alienação e com o conhecimento compartimentado.

Portanto, a interdisciplinaridade, na dimensão pedagógica, se referencia por um conjunto de princípios teóricos produzidos por autores que analisam criticamente o modelo positivista das ciências. Isso resgata o caráter de totalidade do conhecimento a partir de abordagens dialéticas que apontam a ruptura ou/a mudança no paradigma das ciências positivistas, com vistas a reconectar a ciência com os elementos da vida.

Dessa forma, não desconsideramos o ensino disciplinar. Todavia, dado o desenvolvimento da humanidade, uma proposta pedagógica pautada no trabalho escolar de forma interdisciplinar propicia uma formação na perspectiva da totalidade que é fundamental para emancipação humana. A realidade atual demanda que pensemos alternativas para efetivar práticas educativas comprometidas social e politicamente e que tenha a vida o eixo que orienta tudo que será ensinado e apreendido.

Concluímos, assim, que a interdisciplinaridade é uma necessidade decorrente da própria evolução da ciência e da realidade social que é, ao mesmo tempo, una e diversa. E a prática pedagógica nesta perspectiva considera a totalidade social na qual os sujeitos estão inseridos, propiciando, dessa forma, uma educação que possibilite a construção de novas realidades. 


\title{
INTERDISCIPLINARITY: FROM TOTALITY TO PEDAGOGICAL PRACTICE
}

\begin{abstract}
:
This article is based on interdisciplinarity in order to contribute to the understanding of this category. We assume that reality is dynamic, and the subjects who write/draw the circuits of history are influenced by a set of social relations in which they live. Therefore, the theoretical discussions become necessary because they seek to break with the traditional way of knowledge and schools. So, working towards an interdisciplinarity proposal of a school can provide training for human emancipation, in which inserted subjects have the task of making new ways of organizing space considering the social totality. Based on the qualitative nature literature, we will discuss the evolution of science by seeking to present the facts that made possible paradigm changes. We will also discuss about interdisciplinarity as a way to understand phenomena from the perspective of totality and we will conclude by comprehending the interdisciplinary process in pedagogical practice. It was found that interdisciplinarity is a need arising from the evolution of science and social reality that is at the same time one and diverse.
\end{abstract}

Keywords: Interdisciplinary. Totality. Historicity. Social Reality. Pedagogical Practice.

\section{INTERDISCIPLINARIEDAD: DE LA TODALIDAD A LA PRÁCTICA DOCENTE}

\section{Resumen:}

Este artículo trae reflexiones sobre la interdisciplinaridad con el fin de contribuir a la comprensión de esta categoría. Suponemos que la realidad es dinámica, y los sujetos que escriben / dibujan los circuitos de la historia, se ven influenciados por el conjunto de las relaciones sociales en las que viven. Por eso, las discusiones teóricas se hacen necesarias, pues buscan romper con la forma tradicional del conocimiento y de la escuela. Así, trabajar desde la perspectiva de la interdisciplinaridad para una propuesta de una escuela puede proporcionar una formación para la emancipación humana, en la cual los sujetos insertados tienen la tarea de hacer realidad nuevas formas de organizar el espacio, teniendo en cuenta la totalidad social. Con base en la investigación bibliográfica de naturaleza cualitativa, vamos a discutir la evolución de la ciencia buscando presentar los hechos que hicieron posibles los cambios de paradigmas. Presentamos, también, discusiones sobre la interdisciplinaridad como un camino para la comprensión de los fenómenos desde la perspectiva de totalidad y finalizamos comprendiendo el proceso interdisciplinar en la práctica pedagógica. Se verificó que la interdisciplinaridad es una necesidad que surge de la evolución de la ciencia y de la realidad social que es, al mismo tiempo, una y diversa.

Palabras claves: Interdisciplinaridad. Totalidad. Historicidad. Realidad Social. Práctica Pedagógica. 


\section{REFERÊNCIAS}

ALVARENGA, A.T. et al. Histórico, fundamentos filosóficos e teórico-metodológicos da interdisciplinaridade. In: PHILIPPI JR., A; SILVA NETO, A. (Orgs.) Interdisciplinaridade em ciência da tecnologia e inovação. Barueri, SP: Manole, 2011, p. 3-67.

ARANHA, Maria Lucia de Arruda. MARTINS, Maria Helena Pires. Temas de filosofia. $3^{\text {a }}$ edição. São Paulo: Moderna, 2005.

BEER, Max, História do socialismo e das lutas sociais. Tradução: Horácio de Melo. São Paulo: Expressão Popular, 2006

ETGES, Norberto J. Ciência, Interdisciplinaridade e Educação. In: JANTSCH. Ari Paulo, BIANCHETTI. Lucídio, (Orgs) Interdisciplinaridade: para além da filosofia do sujeito. $9^{\mathrm{a}}$ ed. Petropolis, RJ: Vozes, 2011, p.60-94.

FARIA, José Henrique de. Epistemologia crítica, metodologia e interdisciplinaridade. In. PHILIPPI, Arlindo Jr. FERNANDES, Valdir Práticas da interdisciplinaridade no ensino e na pesquisa. Barueri, SP: Manole, 2015.

FAZENDA, Ivani. Interdisciplinaridade: história, teoria e pesquisa. $13^{\mathrm{a}}$ ed. Campinas, São Paulo: Papirus, 2006

FREITAS, Luiz Carlos de. Crítica da Organização do trabalho Pedagógico e da didática. $11^{\mathrm{a} e d}$ ed. Campinas. São Paulo: Papirus, 2012.

FIOD, Edna Garcia Maciel. Interdisciplinaridade na Educação: Algumas Reflexões. In: VENDRAMINI, Celia Regina e AUED, Bernadete. (orgs) Temas e Problemas no ensino em escolas do campo. São Paulo: Outras Expressões, 2012

FRIGOTTO, Gaudêncio. A Interdisciplinaridade Como Necessidade e Como Problema Nas Ciências Sociais. In. Ideação. Foz do Iguaçu/PR, v.10, n.1, 2008 p. 41-62.

Educação Omnilateral. CALDART, Roseli Salete; PEREIRA, Isabel Brasil; ALENTEJANO, Paulo; FRIGOTTO, Gaudêncio (Orgs). Dicionário da Educação do Campo. São Paulo: Expressão Popular, 2012.

KOSIK, Karel. Dialética do concreto, Rio de Janeiro: Paz e Terra, $7^{\text {a }}$ Edição, 1986. 
MARX, Karl. O Capital (Crítica da Economia Política). Livro 1: O processo de produção do capital. 7. ed. DIFEL Difusão Editorial S.A., 1982. vol. 1.

POMBO, Olga. Epistemologia e Interdisciplinaridade. In: Ideação. Foz do Iguaçu/PR, v. $10, n^{\circ} 01,2008$, p. $9-40$

RAYNAUT, Claude. Interdisciplinaridade: mundo contemporâneo, complexidade e desafios à produção e à aplicação de conhecimentos. In: PHILIPPI JR., A; SILVA NETO, A. (Orgs.) Interdisciplinaridade em ciência da tecnologia e inovação. Barueri, SP: Manole, 2011, p. 69-105.

RANIERI, Carli. Antropologia Filosófica. Curitiba: Ibpex, 2009

SANTOS, Boaventura de Souza. Um discurso sobre as ciências. $7^{\text {a }}$ edição. São Paulo: Cortez, 2010.

Artigo:

Recebido em 08 de Fevereiro de 2016.

Aceito em 03 de Novembro de 2016. 